\title{
A catalyst for change
}

\author{
Parul Desai $\mathbb{1}^{1} \cdot$ David Parkins $^{2} \cdot$ Zoe Richmond $^{3}$
}

Received: 15 August 2020 / Revised: 26 August 2020 / Accepted: 1 September 2020 / Published online: 14 September 2020

(c) The Royal College of Ophthalmologists 2020

Managing need and demand for health services equitably remain fundamental requirements of an NHS facing increasing capacity pressures [1]. This is acutely evident for hospital eye services [2, 3]. In England, timely delivery and continuity of NHS eye care is dependent on specific local commissioning (and subsequently provision) of primary and community eye services, in addition to specialist ophthalmic services (hospital sector), and general ophthalmic services (optical sector). Local provision of these additional services has evolved over many years through clinical champions forging good local professional relationships and agreement on clinical protocols, requirements for training and arrangements for governance; such that these commissioned services (e.g. Minor Eye Conditions Services (MECS), glaucoma referral filtering) are available at different levels of maturity, but not uniformly, across the country $[4,5]$.

Over this time, perceptions and attitudes have changed such that the professions involved have embraced development of clinical roles and multi-disciplinary working to support extending the scope and provision of additional services (predominantly by optical practices). The professional bodies and organisations involved have produced standards for training and good practice to deliver this care [6-11]. Where primary eye care services have been commissioned and implemented, improvements in service quality and throughput have been reported [12-15]. However, it is not mandatory for local commissioners to commission these additional services, or for local optical practices or

Parul Desai

parul.desai@nhs.net

1 Public Health and Ophthalmology, Moorfields Eye Hospital NHS Foundation Trust, London EC1V 2PD, UK

2 Kings College Hospital NHS Foundation Trust, Frognal Avenue, Sidcup, Kent DA14 6LT, UK

3 Local Optical Committee Support Unit, LOCSU, 2 Woodbridge Street, London EC1R ODG, UK practitioners to participate in their delivery. This together with the lack of IT infrastructure to support secure data sharing for direct patient care across sectoral boundaries and the challenges for acquiring additional higher qualifications and clinical placements, remain significant barriers for their uptake and implementation, leading to variations not only in the availability and access to services, but also where they are available, their effectiveness.

The CUES (Covid-19 Urgent Eyecare Service) framework was published by NHS England/Improvement (NHSE/I) in April 2020, for service provision in response to the onset of the pandemic [16-18]. Its objectives were to provide a national specification for a service innovation providing safe, local, urgent eye care (in the absence of any regular provision of such care) across an Integrated Care System (ICS) or similar footprint, in England. In doing so, a CUES service would support the wider health system by managing patients away from GP's, A\&E, and hospital eye departments (default locations in the absence of alternative points of access for such services); thereby meeting the health service priorities of the pandemic (immediate and longer term) [17-19], but also those of the NHS Long Term Plan (NHS LTP) [1]. The key principles for the delivery of a CUES service are collaborative, co-management of patients between primary eye care and specialist ophthalmic (hospital based) professionals, based on clinical risk stratification of the patient's presenting condition; supported by the establishment of regular advice and guidance processes to aid clinical decision-making and remote management. Key CUES service enablers are the provision of NHS mail to participating optical practices to facilitate secure sharing of information to support direct patient care; and the service specification providing the technical details for commissioning, contracting and providing the service. The specification also provides criteria for risk stratification endorsed by the professional bodies, and metrics for quality assurance and monitoring of the service.

Whilst the NHS is moving towards commissioning at the level of an ICS population, responsibility for the process of commissioning remains with Clinical 


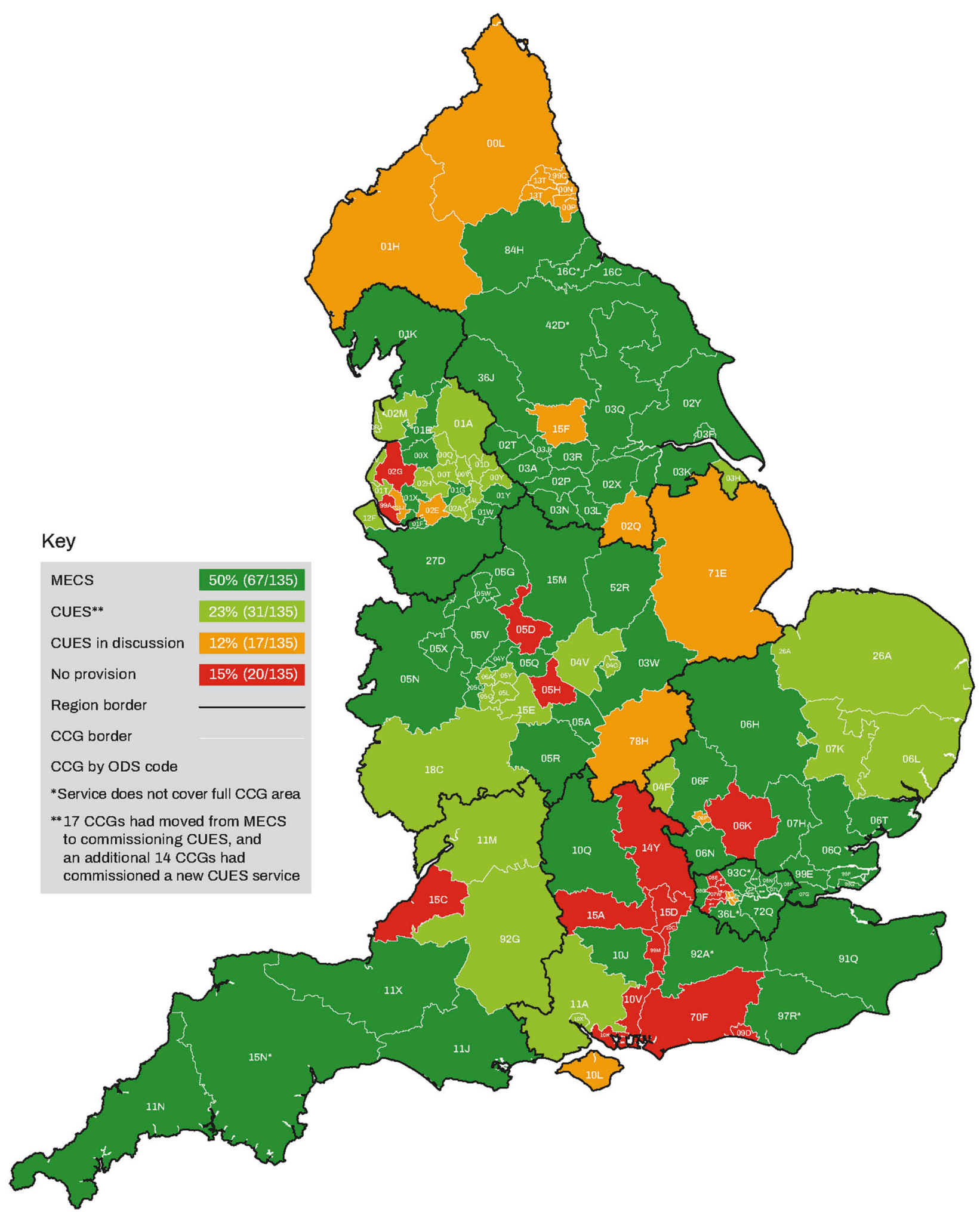

Fig. 1 Distribution of commissioned urgent eye care services by 135 Clinical Commissioning Groups (CCGs), England, at 31 July 2020. (Source: Local Optical Support Unit https://www.locsu.co.uk/).

Commissioning Groups (CCGs) [1]. Prior to CUES, 62\% (84/135) of CCGs had commissioned a MECS type service delivered by optical practices, for the management of common urgent and minor acute eye conditions. By the end of July 2020, 17 of these CCGs had replaced their existing arrangements for MECS with CUES, by building 
on existing local collaborations for service provision and taking advantage of opportunities afforded by new service development and implementation [20]. Fourteen additional CCGs had commissioned a new CUES service from optical practices in areas where services had not been previously available; and a further $17 \mathrm{CCGs}$ were in active discussions for doing the same for their populations [20]. Within just a few months CUES or a pre-existing MECS service was available for the populations of $23 \%$ (31/135) and 50\% (67/135) CCGs respectively, with the potential for providing further CUES coverage shortly (Fig. 1).

As demonstrated by its uptake CUES has met its service objectives, and through its service principles and service enablers it has been a catalyst for change. The CUES Framework and its resources have been well received, not only due to the unique circumstances afforded by the pandemic, but that clinicians, commissioners, provider organisations and health service managers recognise these as being of direct relevance to their area of practice and responsive to their earlier constraints for service development. The service enablers have provided clarity for responsibilities and service scope for consistency in implementation, provided the basis for secure cross-sectoral information sharing and communication between professional groups providing care, and served as a driver for uptake and development of IT platforms [21]. The processes established by the principles for service delivery not only built on existing good practice but notably encouraged professional confidence to participate in service provision where this had previously not been forthcoming. For patients, the uptake and implementation of CUES has facilitated a more equitable distribution of urgent eye care services, reducing the variation in their availability.

Moving forwards, and in keeping with its principles, a CUES service should operate within a service system delivering the full range of urgent and emergency eye services providing continuity of care aligned to clinical need, and an understanding of the responsibilities and relationships between service providers along the pathway of care [22].

The impact of the attributes underpinning CUES and the change in attitudes and service provision that it has introduced is recognised by NHSE/I as the basis for its ongoing approach for transformation and the delivery of the ambitions of the NHS LTP [1, 23]. In doing so the need for a consistent structure for the organisation and delivery of accessible primary eye care services aligned to specialist ophthalmic care, and support services, delivering service systems for populations should be prioritised [24].

\section{Compliance with ethical standards}

Conflict of interest PD is chair of Clinical Council for Eye Health Commissioning (CCEHC www.ccehc.org.uk)—contributed to the development of CUES with NHS England/Improvement. DP is vice chair of Clinical Council for Eye Health Commissioning (CCEHC www.ccehc.org.uk) - contributed to the development of CUES with NHS England/Improvement. ZR is Senior Optical Lead and Interim Clinical Director, Local Optical Committee Support Unit (LOCSU https://www.locsu.co.uk/) and Member of the Clinical Council for Eye Health Commissioning (CCEHC www.ccehc.org.uk) — contributed to the development of CUES with NHS England/Improvement. The authors declare that they have no conflict of interest.

Publisher's note Springer Nature remains neutral with regard to jurisdictional claims in published maps and institutional affiliations.

\section{References}

1. NHS long term plan. 2019. https://www.longtermplan.nhs.uk/. Accessed August 2020.

2. NHS Digital. Hospital Episode Statistics - Outpatient and Admitted Patient Care 2010-2019. https://digital.nhs.uk/data-andinformation/data-tools-and-services/data-services/hospitalepisode-statistics. Accessed August 2020.

3. Elective Care Transformation Programme, NHS England. Transforming elective care services - ophthalmology. 2019. https://www.england.nhs.uk/wp-content/uploads/2019/01/ophtha lmology-elective-care-handbook-v1.1.pdf. Accessed August 2020.

4. Local Optical Committee Support Unit (LOCSU) Services Directory. https://www.locsu.co.uk/commissioning/locsu-servicedirectory/. Accessed August 2020.

5. Henson DB, Spencer AF, Harper R, Cadman EJ. Community refinement of glaucoma referrals. Eye 2003;17:21-6.

6. College of Optometrists. Higher qualifications - Five essential subject areas. 2017-2018. https://www.college-optometrists.org/ cpd-and-cet/training-and-qualifications/higher-qualifications/fiveessential-subject-areas.html. Accessed August 2020.

7. General Optical Council. A Handbook for Optometry. Specialist Registration in Therapeutic Prescribing. https://www.collegeoptometrists.org/cpd-and-cet/training-and-qualifications/quali fying-as-an-independent-prescriber.html. Accessed August 2020.

8. College of Optometrists. Clinical management guidelines. College of Optometrists. https://www.college-optometrists.org/guidance/ clinical-management-guidelines.html. Accessed August 2020.

9. The Royal College of Ophthalmologists. The Ophthalmic Common Clinical Competency Framework (OCCCF). 2016. https://www.rcophth.ac.uk/professional-resources/new-commonclinical-competency-framework-to-standardise-competences-forophthalmic-non-medical-healthcare-professionals/. Accessed August 2020.

10. The Royal College of Ophthalmologists. Standards, publications and research. The Royal College of Ophthalmologists. https://www.rcophth.ac.uk/standards-publications-research/. Accessed August 2020.

11. Local Optical Committee Support Unit and Wales Optometry Postgraduate Educational Centre. Courses to support the development of primary eye care services. 2020. https://www.locsu.co. uk/wp-content/uploads/Files/WhatWeDo/Training/WOPEC_Tra ining/LOCSU-WOPEC-Modules-Booklet-2019.pdf. Accessed August 2020. 
12. Baker H, Ratnarajan G, Harper RA, Edgar DF, Lawrenson JG. Effectiveness of UK optometric enhanced eye care services: a realist review of the literature. Ophthalmic Physiol Opt. 2016;36:545-57.

13. Konstantakopoulou E, Edgar DF, Harper RA, Baker H, Sutton M, Janikoun S, et al. Evaluation of a minor eye conditions scheme delivered by community optometrists. BMJ Open. 2016;6: e011832.

14. Parkins DJ, Edgar DF. Comparison of the effectiveness of two enhanced glaucoma referral schemes. Ophthalmic Physiological Opt. 2011;31:343-52.

15. Mason T, Jones C, Sutton M, Konstantakopoulou E, Edgar DF, Harper R, et al. Retrospective economic analysis of the transfer of services from hospitals to the community: an application to an enhanced eye care service. BMJ Open. 2017;7: e014089.

16. CUES: Covid-19 Urgent Eyecare Service Specification. 2020. https://www.college-optometrists.org/the-college/media-hub/new s-listing/nhs-england-covid-19-urgent-eyecare-service-cues.html. Accessed August 2020.

17. NHS England and NHS Improvement. Optical letter. NHS England and NHS Improvement. 2020. Publications approval reference: 001559. https://www.england.nhs.uk/coronavirus/wp-content/uploa ds/sites/52/2020/04/C0127-optical-letter-1-april-2020.pdf. Accessed August 2020.

18. NHS England and NHS Improvement. Letter to NHS Bodies following declaration of a Level 4 National Incident. NHS England and NHS Improvement. 2020. https://www.england. nhs.uk/coronavirus/wp-content/uploads/sites/52/2020/03/ urgent-next-steps-on-nhs-response-to-covid-19-letter-simonstevens.pdf. Accessed August 2020.
19. Royal College of Ophthalmologists. Preparing eye care services for a potential Covid-19 second wave. Royal College of Ophthalmologists. 2020. https://www.rcophth.ac.uk/wp-content/uploa ds/2020/08/RCOphth-Second-Wave-Guidance-v3.pdf. Accessed August 2020.

20. LOCSU. Services Map. LOCSU. 2020. http://www.locsu.co.uk/w p-content/uploads/2020/08/LOCSU-CCG-Services-Map-A4-Aug2020.pdf.

21. Harper R, Dhawahir-Scala F, Wilson H, Gunn PJG, Jinkinson M, Pretty IA et al. Development and implementation of a Greater Manchester COVID19 Urgent Eyecare Service. Eye. 2020:1-4. https://doi.org/10.1038/s41433-020-1042-6.

22. Clinical Council for Eye Health Commissioning (CCEHC). System and Assurance Framework for Eye-health (SAFE)_Emergency and Urgent Care. Clinical Council for Eye Health Commissioning (CCEHC). 2018. https://www.college-optometrists.org/uploads/a ssets/e827d379-9165-4656-9458c83b0e33da79/SAFE-Emergency-a nd-Urgent-Care.pdf. Accessed August 2020.

23. Clinical Council for Eye Health Commissioning (CCEHC). Priorities for delivering the NHS Long Term Plan for Eye Health. Clinical Council for Eye Health Commissioning (CCEHC). 2019. https://www.college-optometrists.org/uploads/assets/d2837ae145b7-43e2-b0c019e4536b7611/CCEHC-priorities-for-deliveringthe-NHS-LTP-for-Eye-Health-October-2019.pdf. Accessed August 2020.

24. Clinical Council for Eye Health Commissioning (CCEHC). System and Assurance Framework for Eye-health (SAFE)-Overview and Resources. Clinical Council for Eye Health Commissioning (CCEHC). 2018. https://www.college-optometrists.org/the-college/ ccehc/safe-systems-assurance-framework-for-eye-health.html. Accessed August 2020. 